\title{
Liberdade de informação e direito à privacidade: colisão e ponderação
}

\author{
DOI: 10.47224/revista master.v6i11.166
}

\author{
Paulo Roberto Oliveira Santos \\ Lukiã Mendes Silva
}

e-mail:paulo.santos@imepac.edu.br

\section{Resumo}

O presente estudo, fazendo uso da metodologia de abordagem dialética, adotando-se a técnica de pesquisa bibliográfica, teve por objetivo analisar, sob a técnica de ponderação de direitos fundamentais, o embate entre a liberdade de informação e o direito à privacidade, ambos compreendidos como direitos da personalidade, além de estarem inseridos como normas e princípios constitucionais, para explorar a regular solução adotada para a colisão de princípios contraditórios. Pretendeu-se distinguir os fatores que conduzem à colisão de direitos adversos em casos concretos e como dá-se a solução de conflitos normativos. Com foco aplicado nos direitos fundamentais já mencionados, foi dado especial atenção às bases dos direitos da personalidade, à diferenciação de diversos conceitos, imperiosas para o adequado desenvolvimento da pesquisa, e às principais teses de interpretação de normas.

Palavras-chave: Colisão de Princípios. Direitos da Personalidade. Liberdade de Informação. Princípios Constitucionais. Privacidade.

\section{Resumem}

Este estudio, utilizándose de la metodología del enfoque dialéctico, e adoptando la técnica de investigación bibliográfica, tiene como objetivo analizar, bajo la técnica de ponderar los derechos fundamentales, el choque entre la libertad de información y el derecho a la privacidad, ambos entendidos como derechos de la personalidad, además de inseridos como normas y principios constitucionales, para explorar la solución regular adoptada para la colisión de principios contradictorios. Se pretende distinguir los factores que conducen a la colisión de derechos adversos en casos específicos y cómo resolver conflictos normativos. Con un enfoque aplicado en los derechos fundamentales ya mencionados, se prestó especial atención a las bases de los derechos de la personalidad, a la diferenciación de varios conceptos, imprescindibles para el desarrollo adecuado de la investigación, y a las principales tesis de interpretación de normas.

\section{Keywords:}

Colisión de Principios. Derechos de la Personalidad. Libertad de Información. Principios Constitucionales. Privacidad.

\section{INTRODUÇÃO}

Nos últimos anos, a recente expansão do acesso à rede mundial de computadores, em maior parte mediante os atrativos das novas tecnologias e em complementação aos meios de comunicação tradicionais, impulsionou a quantidade, facilidade e velocidade do acesso à informação e publicação de notícias além das informações das mais diversas classes e datas. Obviamente, tal fato amplificou a exposição de fatos e dados de diversas e variadas informações e notícias que geraram certas inconformidades aos sujeitos relacionados em cada matéria. Tal fator, que reflete a relevância da temática que justifica o presente trabalho, vem avivando o debate acerca da liberdade de informação e da responsabilidade dos envolvidos frente à proteção dos direitos da personalidade dos indivíduos sujeitos das matérias produzidas e distribuídas.

Com essa perspectiva, o presente artigo tem como objetivo abordar os aspectos e soluções constantes nos cada vez mais frequentes conflitos, derivados do exercício da liberdade de imprensa, envolvendo o conflito dos princípios constitucionais da liberdade de informação e do direito à privacidade, no contexto constitucional e no âmbito do cotidiano jurisprudencial. Para tanto, inicialmente, serão 
explorados os conceitos essenciais e os principais entendimentos doutrinários, aprofundando nas suas origens, fundamentação, classificação e no papel constitucional que os direitos da personalidade envolvem.

Prosseguindo na temática proposta, será reservado um capítulo de desenvolvimento para cada um dos direitos que participam do embate indicado: o direito à privacidade e o direito ao acesso à informação, também mencionado como liberdade de informação. Em ambos os pontos, em razão da própria limitação do trabalho, será feita a revisão apenas dos entendimentos majoritários consolidados, principalmente no atinente: aos bens tutelados por cada um, à proteção principiológica brindada pela Constituição Federal de 1988, distinções necessárias e outros aspectos particulares de cada um desses direitos.

Afinal, mediante o conjunto de diversas fontes peculiares aos temas abrangidos, pretende-se abordar os instrumentos decisórios de normas percorrendo as técnicas de subsunção e ponderação, a evolução da interpretação jurídica constitucional, para tanto, serão mencionados fatores de surgimento, aplicação de cada um, bem como pretende-se uma introdução à obra de Robert Alexy para clarificar aspectos entre regras e princípios, a colisão entre esses últimos e sua correlata solução. Ainda no mesmo capítulo, para atingir os objetivos propostos, acudidos convenientemente pelo trabalho de Luís Roberto Barroso, entre outros, serão analisados os critérios de ponderação para valoração dos interesses conflitantes abordados, em conjunto à apreciação de parâmetros constitucionais e infraconstitucionais. Pretende-se, ao final, entrever a técnica de ponderação como instrumento de decisão jurídica para solução de conflitos entre normas concorrentes.

\section{2}

\section{DOS DIREITOS DA PERSONALIDADE}

Os direitos da personalidade são aqueles reconhecidos pelo ordenamento jurídico, minuciados na área do Direito Civil referente às relações privadas, como aqueles essenciais para a garantia dos valores inatos do homem. Objeto de diversas divergências doutrinárias, em parte pela sua jovem construção teórica, esses direitos são mais usualmente classificados em três categorias: direitos morais, direitos à integridade física e direitos à integridade psíquica. Neste artigo, nosso interesse encontra-se limitado aos direitos à integridade psíquica que, por sua vez, se desdobra na proteção aos direitos à integridade psíquica da pessoa onde, entre outros, se encontra o direito à intimidade e que, em síntese, objetiva amparar os diversos aspectos da privacidade da pessoa.

Com a evolução da ciência jurídica apreciou-se a conversão de diversos princípios do direito natural para normas positivadas, entre eles, distingue-se, o reconhecimento dos direitos da personalidade. Estes últimos, são conceituados por Gagliano e Pamplona Filho $(2012$, p. 244) como sendo "[...] aqueles que têm por objeto os atributos físicos, psíquicos e morais da pessoa em si e em suas projeções sociais". Assim como por Amaral (2017, p. 353), sendo "[...] situações jurídicas existenciais que têm por objeto os bens e valores essenciais da pessoa, de natureza física, moral e intelectual". Os direitos da personalidade regram através da ordem jurídica a esfera extrapatrimonial do sujeito, ou seja, os aspectos insuscetíveis de representação pecuniária, elementos inatos, ou originários, da pessoa humana.

É aqui que adentramos na discussão do que já se vem observando nas últimas décadas de evolução do Direito brasileiro: a procura por certa coalizão entre a Constituição Federal e o Direito Privado. O movimento conhecido como "constitucionalização do direito privado" que, em poucas palavras, seria a aspiração de se aplicar o Direito Constitucional, através do Direito Privado, como meio de conduzir o projeto e visão da Constituição da República Federativa do Brasil de 1988 - CRFB/88 ao cotidiano dos seus cidadãos, mediante um "processo de elevação ao plano constitucional dos princípios fundamentais do direito civil, que passam a condicionar a observância pelos cidadãos, e a aplicação pelos tribunais, da legislação infraconstitucional" (LOBO, 2018).

O Professor da Escola de Magistratura do Estado do Rio de Janeiro (EMERJ) e desembargador aposentado do TJRJ, Roberto de Abreu e Silva (2001, p. 61) analisa que:

A Carta Magna de 1988, no seu artigo 1으. inciso III, colocou o ser humano como centro de suas atenções, estabelecendo como direito fundamental a dignidade do ser humano. A dignidade representa uma exigência de respeito para com a pessoa no 
exercício da liberdade com responsabilidade por cada um. Esse novo paradigma deve nortear toda interpretação jurídica em sede de responsabilidade civil. A partir de então, não se pode dar um passo em sede de hermenêutica jurídica, sem levar em consideração essa invariante axiológica que é, exatamente, o respeito à dignidade da pessoa humana.

A professora Maria Celina Bodin de Moraes (2003, p. 84) avança de modo antagônico aos autores acima citados, ao expor que o valor da dignidade alcança todos os setores da ordem jurídica, acarretando, na sua decorrência, na impossibilidade de aplicação do princípio constitucional da dignidade da pessoa humana, devido ao seu elevado grau de abstração, pois, "uma vez que a noção é ampliada pelas numerosíssimas conotações que enseja, corre-se o risco da generalização, indicandoa como ratio jurídica de todo e qualquer direito fundamental."

Entende-se que a importância de certos direitos naturais é tanta que resulta consagrado legislativamente no direito positivo, ou seja, passam a se considerar direitos fundamentais. Como melhor exemplo disso temos nossa Constituição Federal de 1988, que, conforme Castilho (2012, p. 195), "representou o ápice do processo de inclusão do país no rol dos países envolvidos com a defesa e a proteção dos direitos humanos", e cuja concepção jurídica outorgou as normas constitucionais força normativa, favorecendo o fundamental colóquio entre as normas constitucionais, civis e penais.

Assim, a absorção da essência da Constituição Federal de 1988 pelas normas concernentes às pessoas (direitos, obrigações, relações, etc) permitiu a recente construção teórica dos direitos da personalidade, junto com sua tutela jurídica nos campos constitucional, civil e penal, tendo como principal fundamento, nas palavras de Amaral (2017, p. 353), o princípio da dignidade da pessoa humana, expresso no art. 1으, inciso III, da Constituição brasileira, "que orienta e legitima o sistema jurídico de defesa da personalidade, que a pessoa humana é o fundamento e o fim da sociedade, do Estado e do direito e, como tal, a eles preexistente".

Em razão da imensa abrangência que a temática dos direitos fundamentais pode alcançar, e por fugir ao interesse principal específico deste trabalho, não aprofundaremos muito mais no tema dos direitos da personalidade, contudo, resulta necessário substanciar, nas palavras de Diniz (2009, p. 74), que "a personalidade é que apoia os direitos e deveres que dela irradiam, é objeto de direito, é o primeiro bem da pessoa". Em outras palavras, se trata de instituto que abarca os direitos da pessoa humana de defender sua integridade física, intelectual e moral. E, apesar de considerados relativamente recentes, os direitos da personalidade são direitos comuns à existência de cada pessoa, e é através dos mesmos que a norma jurídica concede permissão para o indivíduo "defender um bem que a natureza Ihe deu, de maneira primordial e direta (2009, p. 74)."

Por isso, neste trabalho, nosso real interesse quanto aos direitos da personalidade reside entre aqueles que fazem parte da sua ampla classificação, particularmente, nos valores associados à proteção da integridade psíquica e moral das pessoas, com especial ênfase ao direito à privacidade, correlativamente aos da intimidade, esquecimento e imagem, entre outros que não serão plenamente alcançados aqui, tais como: o segredo pessoal e doméstico; a honra; a identidade pessoal, familiar e social; a segurança moral; e o aspecto moral da estética humana.

Com igual intuito, ainda, domina a necessidade de introduzir os direitos à comunicação, expressão e informação, os quais, nos ensinamentos de Bittar (2015, p. 166-167), se agrupam no grupo de direitos de cunho psíquico essenciais à personalidade humana. No ordenamento jurídico, o direito à informação, protagonista neste estudo, é abrangido pela proteção conferida às liberdades de expressão, de pensamento, de comunicação e de imprensa as quais, "[...] oferecem reflexos na vida de relação com os outros em sociedade, e, portanto, se mostram interessantes para o direito [...], obedecidas as normas de ordem pública a que, coercitivamente ou sob sua vontade, se submete $(2015$, p. 167)."

Todavia, para alcançar nosso objeto de trabalho, previamente, é necessário, diferenciar dois conceitos frequentemente considerados sinônimos: os direitos fundamentais e os direitos da personalidade.

Concorde Bittar (2015, p. 56), os direitos fundamentais, também denominados direitos do homem, possuem efeito de proteção ante o Estado, 
enquanto os direitos da personalidade consideram "os mesmos direitos, mas sob o ângulo das relações entre particulares, ou seja, da proteção contra outros homens." Outra distinção importante feita pelo autor trata que os direitos naturais (entre eles o da personalidade), "situam-se acima do direito positivo", e que, mesmo não contemplados pela legislação, persistem em face da noção transcendente da natureza humana. Enquanto os direitos fundamentais seriam aqueles que, "com o reconhecimento do Estado, passam do direito natural para o plano positivo" (BITTAR, 2015, p. 57).

Contudo, ainda sobre a distinção dos termos acima, mas também conexo ao aspecto da constitucionalização do direito privado, Bittar (2015, p. 60-61) manifesta que:

[...] nas duas últimas décadas, uma tendência à consolidação da visão de que a dicotomia entre público e privado cedeu lugar para uma fundamentação unificada da luta por efetividade dos direitos no sentido da plena realização da dignidade da pessoa humana, em suas diversas manifestações. [...] Assim, o alcance dos direitos fundamentais toca a dimensão civil-privada, e, nesse sentido, como indicam os estudiosos da matéria, a exemplo de Ingo Wolfgang Sarlet, a eficácia horizontal dos direitos fundamentais torna possível sua incidência sobre as relações privadas.

A Constituição Federal de 1988 já discerniu o potencial conflito entre o exercício dos direitos da personalidade ante a equivalente garantia às liberdades de expressão e informação, entre outros, assim, a carta constitucional assentou em seu texto - art. 5o, incisos V e X, - a proteção aos supracitados direitos, além de eventual indenização pelos danos causados, outorgando-lhes proteção e tratamento constitucional ao considerá-los como essenciais à pessoa humana. Notoriamente, apresentado conflito, inevitavelmente, não supõe na supressão de um dos lados, mas sim na imperiosa coalizão e assenso mútuo entre a liberdade de expressão e comunicação e a privacidade e honra das pessoas envolvidas.

\section{DO DIREITO À PRIVACIDADE}

O avanço tecnológico, principalmente na figura da internet, veio acompanhado pelo surgimento de diversas visões e receios de parcela da população e autoridades que reprisavam a percepção e o temor de que, juntamente aos novos meios de comunicação, tecnologias (computadores, câmeras de vigilância, webcams, celulares etc), e seus respectivos alcance e tratamentos socioculturais, adviriam novos modos e espécies de delitos e violações de direitos, cujos autores, munidos pelo anonimato e pela distância, não poderiam ser perseguidos e responsabilizados.

No mesmo âmbito, o incremento e a melhoria de distribuição de informações e comentários desfavoráveis sobre alguém - muitas das vezes consideradas afrontosas à sua privacidade e imagem pessoal -, não se encontra, nem nunca foi limitado ao domínio digital. Assim, para poder avistar potenciais abusos dos exercícios de liberdade de informação e expressão basta que observemos a algumas das esferas mais tradicionais e comuns utilizadas para comunicação e expressão, seja a pequena ou grande mídia, como um noticiário televisivo de alcance nacional ou um jornal/rádio local, seja através de livros como por exemplo as tão populares e polêmicas biografias; ou num debate, numa simples conversa ou troca de comentários.

Nossa vigente Constituição Federal de 1988 estabeleceu em seu art. 50, inciso $X$, inclusive como cláusula pétrea, a inviolabilidade da intimidade, da vida privada, da honra e da imagem das pessoas como garantia fundamental individual, reconhecendo desta forma a estes tópicos uma importância essencial, merecedora da completa proteção do ordenamento jurídico pátrio, tendo, inclusive, previsto a correspondente indenização civil pela sua eventual violação, até mesmo no âmbito online.

Com relação aos direitos à vida privada - ou à privacidade - e à intimidade, denota-se o fato de possuírem conceitos semelhantes, porém distintos, contudo, ambos tratam de direitos da personalidade que, fazem referência ao controle que a pessoa, natural ou jurídica, é capaz de aplicar para gerenciar os aspectos da sua esfera privada que não deseja expor ao conhecimento público ou de terceiros, e através do qual, "o sujeito, pode impedir intromissões vedando qualquer invasão em sua 
esfera privada ou íntima, [...] inclusive via internet. (DINIZ, 2009, p. 163).

Bentivegna (2019, p. 95) aponta que os incisos V e $\mathrm{X}^{1}$ da Constituição Federal de 1988, concederam, respectivamente, à pessoa que sentiu sua privacidade importunada, a capacidade de poder exigir o direito de resposta contra o que foi divulgado, bem como querer provar o suposto abuso na atuação da liberdade de informação ou expressão, inclusive judicialmente para possível responsabilização e sequente reparação mediante indenização pelos danos sofridos. $\mathrm{O}$ autor salienta a contenda de interesses que se dão no plano da Responsabilidade Civil, onde o abuso da liberdade de informação, pela eventual difusão de informações e pensamentos "que não atendam ao real interesse público," é limitado, controlado, pelo direito alheio à vida privada e à honra, elementos tão fundamentais para a satisfação do psíquico, personalidade e dos sentimentos de dignidade e honra de cada um de nós.

Prossegue analisando Bentivegna (2019, p. 148) que, o direito à privacidade surge no desígnio de sustentar a proteção da intimidade e vida privada das pessoas que assim o reivindiquem, e delinear a natureza e 0 alcance desta proteção, desenvolvendo-se, inclusive, mais predominantemente através de uma construção jurisprudencial do que por imposições legislativas. Entendendo, o autor, que:

Para se garantir a privacidade, abrangente das invioláveis intimidades e vida privada, deve-se protegê-la não apenas no recôndito do recolhimento doméstico, mas em todas as contingências das interações da vida social ou profissional, onde é direito da pessoa manter-se preservada em sua privacidade até o limite de sua escolha pessoal. Cabendo ao titular do Direito à Privacidade delimitar os espaços de sua vida que serão abertos à visitação da curiosidade alheia e aqueles interditados a qualquer penetração, vistoria ou averiguação alheias.
Nesse norte, Miranda desenvolve que o "[...] direito subjetivo fundamental de privacidade atribui ao indivíduo a faculdade de constranger os outros ao respeito de sua individualidade e mesmo a resistir à violação do que lhe é próprio" (2016, p. 100). Assim, vê referido direito como proteção jurídica facultativa pela qual seu titular aspira a inibir a notabilidade ou exposição pública de fatos pessoais e particulares, continuando a mantê-los sob o abrigo da esfera privada ou íntima.

Miranda (2016, p. 104), ainda, sobrevém agregando que, atualmente, a proteção ao direito à privacidade destaca-se, principalmente, na sua real efetividade. De certo modo, o advento da era digital, mediante o amplo exercício de coleta e utilização de informações, promoveu o deslocamento do foco de debate para não mais a conceituação e embasamento, mas, sim, para a efetiva aplicação do direito. Nas suas palavras:

\begin{abstract}
A tutela que se tem concedido à privacidade não se afigura idônea à contenção das sucessivas violações que se tem perpetrado no ambiente social, especialmente virtual. [...] 0 direito à privacidade precisa ser revisitado para que se possa compreender que o conteúdo jurídico tutelado deve ser efetivamente respeitado, qualquer que seja o espaço meio - em que se perpetrem as infringências (2016, p. 104).
\end{abstract}

Paesani (2014, p. 13) menciona a opinião do magistrado italiano Renato Borruso, conforme a qual "o computador entrou no mundo do direito despertando os atrasos, as cautelas, a perplexidade e as desconfianças que circundam os novos fenômenos." Continua expondo duas reações evidenciadas no mundo jurídico: a desconfiança e a defesa, caracterizadas, respectivamente, pelo confronto e exclusão das novas tecnologias na procura de neutralizar "forças invasoras" subversivas. Esta visão é contraposta pelas premissas da liberdade de informação,

1 Art. 5o Todos são iguais perante a lei, sem distinção de qualquer natureza, garantindo-se aos brasileiros e aos estrangeiros residentes no País a inviolabilidade do direito à vida, à liberdade, à igualdade, à segurança e à propriedade, nos termos seguintes: [...]

$V$ - é assegurado o direito de resposta, proporcional ao agravo, além da indenização por dano material, moral ou à imagem; $X$ - são invioláveis a intimidade, a vida privada, a honra e a imagem das pessoas, assegurado o direito a indenização pelo dano material ou moral decorrente de sua violação; 
especialmente, quanto às novas aplicações digitais, concorde abordaremos no capítulo a seguir.

À medida que a velocidade, o alcance e a facilidade das comunicações avançam, a eventual ameaça a privacidade tende a atingir maior discussão e, por conseguinte, maior proteção. Contudo, devem-se levar em consideração a constante mudança dos comportamentos sociais e institucionais, a teoria dos círculos concêntricos da vida privada², e os fatos constitutivos próprios cada envolvido no caso concreto, valiosos mecanismo de avaliação às hipotéticas afrontas ao direito à privacidade das pessoas, frente a eventuais excessos ou não da liberdade de informação, e demais direitos abrangidos, no contexto dos sistemas judiciais (constitucional) e da informação, esses, cada mais complexos e articulados.

\section{4}

\section{DA LIBERDADE DE INFORMAÇÃO}

É com a apreciação de uma segunda cláusula pétrea que nossa temática de pesquisa se complementa: a da liberdade de informação, que, fixada nos arts. 5o, incisos IX e XIV , e art. 220 da Constituição Federal de 1988, e entendida como direito derivado das liberdades de expressão e comunicação, assegura a todos a possibilidade de conceder e aceder livremente à informações, sejam: dados ou fatos; orais, escritos, impressos ou representados pelas artes visuais; próprio da mídia tradicional (jornais, revistas, comerciais, anúncios impressos em revistas/jornais e outdoors, rádios, etc) ou nos mais diversos formatos da mídia digital (sites, redes sociais, plataformas de vídeos, e-mail, etc).

De certa forma, pode-se dizer que a previsão pessimista mencionada no anterior tópico se viu concretizada, contudo, a níveis mais equitativos aos benefícios e oportunidades - conforme refletem nos mais diversos aspectos da nossa realidade. Logo, cabe ressaltar o importante papel que o uso das mais recentes tecnologias vem contribuindo para a resolução, responsabilização e reparação de ofensas praticadas tanto dentro como fora das novas tecnologias de informação e comunicação.
Inicialmente, é preciso expirar qualquer entendimento ambíguo que corriqueiras alusões possam ter gerado ao leitor mais alheio ao âmbito jurídico, uma vez que - sendo oportuno reconhecer - tanto "privacidade" como "informação" são termos que detém uma ampla percepção subjetiva, suscetíveis de distorções por convicções políticas e ideológicas.

Posto isto, mostra-se fundamental elucidar que a liberdade de expressão não se confunde com a liberdade de informação. O primeiro conceito, conforme se extrai dos ensinamentos de Cavalieri Filho (2019, p. 158), "nada tem a ver com fatos, com acontecimentos ou com dados ocorridos. Tudo se passa no mundo das idéias, sem qualquer compromisso com a veracidade e a imparcialidade."

Já, na liberdade de informação, de acordo com Silva $(2012$, p. 49) se requer um exercício mais cuidadoso e apurado, objetivo e impessoal, onde a veracidade da referência é condição indispensável para ensejar sua proteção. Do mesmo modo, é preciso diferenciar entre o que é o relato objetivo dos fatos e o que compõem uma ofensa simulada, das mais diversas formas, através dos diferentes meios de comunicação disponíveis, seja intencional ou inconsciente, pois independentemente da noção do agente ativo tal conduta pode estar sujeita a penalidades legais.

Conforme apontado por Bentivegna (2019, p. 81), diferentemente do que ocorre com a liberdade de expressão, o eventual autor de afirmação, a qual venha a ser imputada agravo contra direito alheio, para vir a se valer da proteção da liberdade de informação deverá "provar a verossimilhança da informação veiculada - não a verdade absoluta, que é inatingível - o que não ocorre com quem exerce sua liberdade de expressão" por ter emitido um juízo de valor sobre alguém através de manifestação artística, por exemplo."

Bentivegna $(2019$, p. 82) prossegue desenvolvendo que, quando a Constituição Federal de 1988 incluiu os princípios da Liberdade de Expressão e da Liberdade de Informação, ao igual do que ocorre com todos os outros direitos e garantias

2 Ideia na qual pressupõe-se a existência de espaços próprios ao desenvolvimento da personalidade nos âmbitos públicos e privados. De acordo com esta teoria, é possível diferenciar o âmbito privado em três esferas concêntricas (compartilhando o mesmo eixo). Na esfera mais superficial, e mais abrangente, encontra-se a da vida privada, em síntese, refere-se aos assuntos que o sujeito não quer que se tornem públicos; em seguida, envolvendo a esfera central, temos a esfera da intimidade, limitada apenas às pessoas da intimidade do indivíduo; e por último, a do segredo, esfera mais reduzida, apta apenas ao seu indivíduo. (Barroso, 2007, p. 76). 
fundamentais, não veio a criar um direito absoluto ou ilimitado, pois, como visto anteriormente, a mesma constituinte "trouxe, a par da garantia desses direitos e liberdades, as hipóteses de seu temperamento ante os eventuais danos causados às pessoas ao as exigências relativas às suas vidas privadas, honras e imagens."

Assim, devemos preceder o estudo quanto a percepção da relevância que as liberdades de informação e expressão alcançaram no nosso contexto histórico-social, acudidos pela obra de Alexandre Sankievicz, colhem-se diferentes teorias acerca da razão, da fundamentação, da liberdade de expressão. Originalmente trabalhadas unicamente sobre a liberdade de expressão, entendemos que as visões e percepções apresentadas sobre a liberdade de expressão, também são aplicáveis, e convenientes, à liberdade informação, como veremos adiante.

Não nos podendo permitir aprofundar, como bem gostaríamos, no estudo dos conceitos e ensinamentos, devemos limitarmos as principais funções que assentam debatidas liberdade como merecedoras de proteção maior. Sankievicz comenta o papel da liberdade de expressão na garantia da busca da verdade dentro das atividades sociais e do desenvolvimento da democracia, seja na eleição de governantes, seja na deliberação e promulgação de normas e políticas em geral. Não obstante, o mestre em direito constitucional realça a função da liberdade de expressão como manifestação da autonomia e dignidade individual que concede ao se titular "a capacidade de desenvolver todo o seu potencial, controlar o seu próprio destino e influenciar as decisões coletivas" (2011, p. 22-23), assim, racapitula Sankievicz (2011, p. 22), que:

[...] a liberdade de expressão deriva antes de tudo de um imperativo moral fundado na proteção da autonomia individual. Deve ser constitucionalmente protegida, não porque viabiliza um desejado resultado, como a busca da verdade ou a livre circulação de ideias em uma sociedade democrática, mas porque o respeito ao indivíduo leva, consequentemente, à proteção das comunicações que definem, desenvolvem ou protegem o seu ser.
Independentemente do contexto de atuação, é inegável que o direito individual à liberdade da pessoa é direito fundamental, estando garantido em nosso ordenamento jurídico, não só constitucionalmente, como previamente visto, como, também, à luz da teoria geral da tutela dos direitos da personalidade, estabelecendo-se medidas e instrumentos imprescindiveis para possibilitam seu resgate, bem como o afastamento de eventual cerceamento, contra o Estado e/ou particulares, assegurando, ainda, a reparação de danos, tanto morais como patrimoniais (BITTAR, 2015, p. 170).

Isto posto, conclui-se que a proteção da liberdade de informação, e congêneres, é tutelada em razão de sua relevante importância e riqueza ao sistema político, democrático, jurídico e social, entre outros. Assim, a Constituinte, percebeu-a não como uma ameaça, mas, sim, como componente essencial ao desenvolvimento do espírito da Constituição Federal de 1988. Contudo, vale repetir que, obviamente, não disponibilizou seu uso abusivo ou direcionado ao agravo de terceiros, assim, lidando através do, por assim dizer, "mecanismo inverso" previu a responsabilização dos autores e a proteção à privacidade (além da honra, imagem, intimidade e segredo) dos ofendidos nos casos de excesso ou ofensa. Destarte, ante o evidente conflito de princípios/garantias hierarquicamente concordes, surgiu a necessidade de obter-se uma solução constitucionalmente adequada às lides deles resultantes.

\section{DA TÉCNICA DE PONDERAÇÃO}

Em um estado democrático amplamente principiológico e garantista na proteção ao núcleo essencial dos direitos fundamentais - vertente do novo constitucionalismo consistente em um conteúdo mínimo garantido, vinculado, até mesmo frente eventual intervenção legislativa diversa ${ }^{3}$ resulta inevitável o choque de direitos fundamentais, princípios constitucionais, como, no caso concreto, os da expressão e da informação.

De acordo com Sarlet, Marinoni e Mitidiero (2019, p 225), e Barroso (2007, p. 69), a necessidade de 
resolver tensões concretas, cada vez mais frequentes no direito constitucional contemporâneo, entre direitos protegidos igualmente com posição jurídica de cláusulas pétreas; e a insuficiência da interpretação jurídica tradicional, fundada no assentamento entre o fato ocorrido e a interpretação da previsão da norma legal identificada (técnica de subsunção ou método subsuntivo), para com a solução de problemas jurídicos e a aplicação do direito concreto, promoveram o desenvolvimento da técnica de ponderação, ou balanceamento, de bens.

No ainda referente a interpretação jurídica tradicional, Barroso (2007, p. 64) expressa que "a interpretação jurídica tradicional, portanto, tem como principal instrumento de trabalho a figura normativa da regra", prossegue complementando que a referido método de solução "[...] reserva ao intérprete um papel estritamente técnico de revelação do sentido de um Direito integralmente contido na norma legislada." Conclui afirmando que, apesar de ainda ser relevante à procura do sentido das normas e à solução de casos concretos, o método tradicional nem sempre é suficiente (2007, p. 65).

Por outro lado, ao introduzir a matéria da moderna interpretação constitucional, Barroso leciona que, diferente da interpretação tradicional, aquela diferencia-se desta última ao relevar a primazia da abstração da norma e conceder ao intérprete do caso, parcela da função decisória (2007, p. 65). Assim pois, extrai-se que a evolução da técnica de interpretação legislativa variou ao suprimir o caráter vinculante da norma e ao transferir o poder decisório dela, do legislador ao intérprete responsável pela sua aplicação ao confiar e depender da valoração deste último. É então que, "como técnica de raciocínio e de decisão [que] a ponderação passa a conviver com a subsunção" (BARROSO, 2007, p. 97).

Por sua vez, Sarlet, Marinoni e Mitidiero (2019, p 225), trabalham com a explicação de Gomes
Canotilho ${ }^{4}$, na qual o jurista português atribui outros três fatores - diversos daqueles de Barroso, supramencionados - para o surgimento do método, ou técnica, de ponderação, são eles:

(a) a inexistência de uma ordenação hierarquizada e abstrata de bens constitucionais; (b) a estrutura de princípio de muitas normas constitucionais, que, por sua vez, implica a refutação de uma lógica do "tudo ou nada" e, portanto, exige a otimização e harmonização de tais princípios, especialmente nos casos de conflito; (c) a possibilidade de uma diversidade de leituras dos conflitos de bens constitucionais em face de uma ausência de unidade de valores no âmbito da comunidade política, impondo cuidadosa análise dos bens em causa e uma rigorosa fundamentação no âmbito da resolução dos conflitos.

A solução de atritos normativos com interesses ou bens conflitantes de igual patamar representa cenário no qual a mera interpretação dos textos normativos dos elementos confrontantes resulta ineficaz.

Assim, cabe ao operador do direito responsável por interpretar as normas debatidas, através da interpretação constitucional e infraconstitucional, a função de decidir e convencer aos envolvidos. Ocorre que, a norma que compõe o ordenamento jurídico e objetiva atuar sobre o plano dos fatos muitas vezes não opera como regra, mas como princípio, e ante a eventual contraposição de princípios e direitos de igual aplicação, ainda que abstrata, nasce o dever do intérprete de verificar e valorar a eventual prevalência dos interesses pleiteados 5 .

A ausência de relação de precedência entre os princípios constitucionais, como os aqui abordados, derivam na lei de colisão de Robert Alexy, destaque

4 CANOTILHO, José Joaquim Gomes. Direito constitucional e teoria da constituição. 3. ed. Coimbra: Almedina, 1999 (p. 1.237).

5 Nos termos do artigo 489 do Código de Processo Civil brasileiro em vigência, são elementos essenciais da sentença:

$[\ldots]$

$\S 2$ ㅇ No caso de colisão entre normas, o juiz deve justificar o objeto e os critérios gerais da ponderação efetuada, enunciando as razões que autorizam a interferência na norma afastada e as premissas fáticas que fundamentam a conclusão.

§ 3ำ A decisão judicial deve ser interpretada a partir da conjugação de todos os seus elementos e em conformidade com o princípio da boa-fé. 
em sua teoria sobre os direitos fundamentais. Assim dispõe:

Esta ley, que será llamada "ley de colisión", es uno de los fundamentos de la teoría de los principios aquí sostenidos. Refleja el carácter de los principios como mandatos de optimización entre los cuales, primero, no existen relaciones absolutas de precedencia y que. segundo. se refieren a acciones y situaciones que no son cuantificables. Al mismo tiempo, constituye la base para restar fuerza a las objeciones que resultan de la proximidad de la teoría de los principios con la teoría de los valores (1993, p. 94-95).

Resulta prudente trazer, brevemente, a teoria sobre os princípios e regras de Alexy (1993, p. 99-100), na qual, adotando o critério da estrutura da norma, aduz que a diferença entre referidos institutos, entre outras diferenciações, reside em que enquanto os princípios ordenam o cumprimento em ampla medida, sem estabelecer certo grau, as regras possuem cumprimento direto do que é por elas estipulado. Ainda, enquanto aqueles "apresentan razones que pueden ser desplazadas por otras razones opuestas" (p. 99), essas (regras) não são deslocadas - desplazadas - ainda que esteja sustentada por um princípio oposto de menor peso, esse, sim, eventualmente deslocado.

Correlato a Alexy, Humberto Bergmann Ávila (1999, p. 156) disserta acerca da distinção entre regras e princípios através dos critérios de: grau de abstração, generalidade da prescrição normativa e fundamento de validade. Através deles, os princípios distinguem-se das regras ao projetarem suas orientações (ideias, valores), decorrente da noção do Estado de Direito (fundamento de validade), a um número indeterminado de pessoas e a um número indeterminado de circunstância (maior abstração e generalidade); enquanto as regras são mais específicas, típicas e concretas para com as condutas e consequências ditadas (menor grau de abstração e generalidade) pelos textos normativos (fundamento de validade).

Concluímos o entendimento de Alexy, no qual sustenta que ante razões equitativamente válidas ou havendo dúvida na decisão do caso concreto, diferentemente do que ocorre com as regras que, no Brasil, regem-se por critérios de hierarquia, cronologia e especialização, não se busca a prevalência de um princípio sobre outro, excetuando aqueles 'princípios absolutos', mas, sim, das condições nas quais um princípio precede ao outro, e do peso de cada um deles ante o conflito concreto. Assim ministra o clássico professor Alexy:

Este "conflicto", como el Tribunal llama a veces a la colisión, no es solucionado declarando inválido a una de ambas normas, sino a través de una "ponderación" en la que ninguno de los dos principios [...] "puede pretender una precedencia básica". Más bien, habría que "decidir cuál interés debe ceder, teniendo en cuenta la conformación típica del caso y las circunstancias especiales del caso particular". No es posible una descripción más precisa de una colisión de principios. Dos normas, tomadas en sí mismas, conducen a resultados recíprocamente contradictorios. Ninguna es inválida, ninguna tiene una precedencia absoluta. Qué sea lo que aquí vale depende de cómo haya que decidir en vista de las circunstancias del caso (1993, p. 96).

Outrossim, ao se abordar um prognóstico de conflito entre princípios constitucionais, inicialmente, já deve despontar na mente do intérprete que, como regra, não será cabível a aplicação dos tradicionais critérios de solução de antinomias jurídicas (hierárquico, cronológico e de especialidade) ${ }^{6}$. No caso daqueles que envolvam direitos fundamentais percebe-se uma maior complexidade de análise, uma vez que os direitos fundamentais possuem o mesmo posicionamento jurídico na condição de cláusulas pétreas por força do artigo $60, \S 4$ ? , inciso IV, da Constituição Federal.

É para essa conjuntura que Luís Roberto Barroso, em seu estudo "Liberdade de expressão versus direitos da personalidade. Colisão de direitos fundamentais e critérios de ponderação", nos apresenta a técnica de ponderação como espécie de raciocínio para decisão jurídica em conflitos específicos, como na hipótese envolvendo as liberdades de informação e 
expressão e os direitos da personalidade, já trabalhados aqui. Assim leciona:

[...] O princípio da unidade da Constituição não admite que o intérprete simplesmente opte por uma norma e despreze a outra também aplicável em tese, como se houvesse hierarquia entre elas. Como consequência, a interpretação constitucional viu-se na contingência de desenvolver técnicas capazes de lidar com o fato de que a Constituição é um documento dialético - que tutela valores e interesses potencialmente conflitantes - e que princípios nela consagrados entram, frequentemente, em rota de colisão.

Destarte, ante a aqui deficiente aplicação da técnica de subsunção, ergue-se a técnica de decisão da ponderação, estruturada no "balanceamento e sopesamento de interesses, bens, valores ou normas" (BARROSO, 2007, p. 72), através de um processo que, de forma simples e direta, Barroso deslinda em três etapas.

A etapa inicial (primeira) da técnica de ponderação é aquela na qual o intérprete identifica o conflito entre os elementos normativos aportados. Na etapa seguinte (segunda) é quando ocorre a análise e interpretação dos fatos e circunstâncias evidenciadas no caso concreto, interpretação que se dá à luz das normas anteriormente identificadas visando-se alcançar as aplicações e alcances destas.

É na terceira e última etapa da ponderação, diferentemente do que ocorre na subsunção, que se procede ao exame conjunto das normas e fatos a fim de conferir os pesos atribuídos a cada fundamento confrontado para assim indicar a solução obtida para o caso concreto, ou seja, declarar qual grupo de normas deverá prevalecer e aplicar-se ante a colisão de direitos fundamentais apresentados conforme os elementos dos fatos do caso analisados.

Diante disso, segue Barroso, já adentrando nas particularidades entre os direitos à privacidade e a liberdade de informação, entre outros, apresentando alguns elementos a se examinar na ponderação (terceira etapa).

Inicialmente, destacam-se os parâmetros constitucionais como: a veracidade do fato, ligando à diferença entre liberdade de expressão e liberdade de informação, bem como condição indispensável para ensejar a proteção desta última, conforme visto no capítulo anterior; a licitude do meio através do qual obteve-se a informação, uma vez que, além de envolver preceitos constitucionais de obtenção de provas e meios ou fontes criminosas de acesso à informações, também aborda a disponibilidade de acesso à informação que se desaprova, e o prévio consentimento ou não do interessado; oportunidade de argumentação relativa aos indícios e circunstâncias de eventual consentimento tácito, por exemplo. Adverte Barroso:

Note-se ainda que a circunstância de a informação estar disponível em arquivos públicos ou poder ser obtida por meios regulares e ilícitos torna-a pública e, portanto, presume-se que a divulgação desse tipo de informação não afeta a intimidade, a vida privada, a honra ou a imagem dos envolvidos (2007, p. 88).

Seguem os parâmetros para ponderação através da consideração da personalidade pública ou privada do sujeito da notícia, apura-se uma imprecisa distinção na proteção de pessoas notórias frente aquelas, digamos, corriqueiras, novamente, cabe reportar-se à teoria dos círculos concêntricos citada no segundo capítulo do presente artigo. Consumando sobre a personalidade da pessoa, traz Barroso:

Ainda no campo do direito da privacidade, a doutrina e a jurisprudência costumam identificar um elemento decisivo na determinação da intensidade de sua proteção: o grau de exposição pública da pessoa, em razão de seu cargo ou atividade, ou até mesmo de alguma circunstância eventual. A privacidade de indivíduos de vida pública - políticos, atletas, artistas - sujeita-se a parâmetro de aferição menos rígido do que os de vida estritamente privada. [...] Remarque-se bem: o direito de privacidade existe em relação a todas as pessoas e deve ser protegido. Mas o âmbito do que se deve interditar à curiosidade do público é menor no caso das pessoas públicas (2007, p. 76).

Também, deve-se cuidar das medidas empregadas conforme o local e natureza do fato em virtude dos fatores de exposição (locais de acesso público ou privado, de concentração de pessoas ou de acesso restrito) e interesse jornalístico (crimes, acidentes, incêndios, desastres ambientais etc.) e a ampla diferença que podem representar para o contexto fático da disputa. Outrossim, confinante ao 
interesse jornalístico, há especial destaque para o interesse público na divulgação do fato. Acorde acrescenta Bittar (2015, p. 177), "deve-se ter presente, a respeito, a predominância do interesse coletivo sobre o particular, cabendo verificar-se, em cada caso, o alcance respectivo, a fim de não se sacrificar, indevidamente, a pessoa e, com isso, permitir-lhe a reação jurídica compatível." Aprimora Barroso (2007, p. 90) cuidando da divulgação de fatos relacionados com a atuação de órgãos públicos e a publicidade como instrumento de controle popular inerente ao regime republicano, regra constitucional limitada apenas pela segurança da sociedade e do Estado (CF/88, art. $5^{\circ}$, inciso XXXIII).

No mesmo rumo, Barroso, também defende como parâmetro constitucional a preferência da liberdade de informação e de expressão frente a proibição prévia de divulgação - isso, sim, com o primeiro reconhecimento da veracidade dos fatos, a licitude dos meios e a presunção do interesse público na divulgação do feito (como regra ${ }^{7}$ ) -, cabendo, nos casos impróprios, aqueles envolvendo abuso de liberdade e violação de privacidade, os correspondentes mecanismos de sanção/reparação (retificação, retratação, responsabilização e direito de resposta, por citar alguns).

Por fim, encerrando o exame de ponderação, Barroso ingressa na análise sob o enfoque infraconstitucional, entendendo, sucintamente, na inviabilidade de eventuais normas infraconstitucionais alcançarem a pretensão de lograr arbitrar uma colisão de direitos pariformes entre si. Conclui o professor (2007, p. 91):

Não é de surpreender, portanto, que o legislador fosse atraído pela ideia de criar soluções gerais para o tema. Relembre-se, no entanto, como já assinalado, que uma lei que pretenda arbitrar uma colisão de direitos fundamentais de forma rígida e abstrata enfrentará dois óbices principais e interligados - a unidade da Constituição e a ausência de hierarquia entre os direitos -, que levam à mesma consequência: a ausência de fundamento de validade para a preferência atribuída a um direito em detrimento de outro em caráter geral e permanente.

Perante o exposto, extrai-se o entendimento, validado e fortalecido, de que ante a ocorrência de colisão normativa, seja entre princípios seja entre regras, especialmente envolvendo direitos fundamentais e constitucionais, a técnica de ponderação sobressai ante os critérios de solução de conflitos tradicionais, já abordados. Conjuntamente, entende-se que, vinculado à ausência da capacidade de adotar-se soluções gerais para solução dos conflitos, impera a análise individual, caso a caso de cada um dos embates que venham a surgir, cumprindo a ao intérprete hábil o dever de explorar e desenvolver, conjuntamente, os fatos e suas circunstâncias a as normas conflitantes envolvidas ensejadas por cada uma das partes, visando consumar a solução mais adequada ao caso concreto, isso, sempre tencionando o amparo legal constitucional e o convencimento dos destinatários do julgamento.

\section{CONSIDERAÇÕES FINAIS}

Diante do conjunto pesquisado, cumpre abordar as lições alcançadas. Previamente, cabe apontar caráter habitual e cada vez mais controverso, com destaque aos âmbitos políticos, midiáticos e institucionais. Reconhecida a atuação das novas tecnologias, todavia, não se pode deixar de recordar que os conflitos entre liberdade de informação e direito à privacidade funde-se à própria sociedade e seu desenvolvimento. Assim, ante o colossal espectro disponível, resolvemos priorizar a presente pesquisa partindo do marco e amparo da Constituição Federal de 1988, cuja atuação mostrou-se essencial para que a dignidade da pessoa humana seja reconhecida com um dos fundamentos do Estado Democrático de Direito, para a consagração e defesa dos direitos da personalidade - além do responsável exercício das liberdades individuais concedidas.

É ante os casos em que surge uma colisão entre o direito da proteção da integridade moral da pessoa

7 Segundo Luís Roberto Barroso (2007, p. 93-94) “[...] sendo que a presunção de legitimidade da divulgação somente cederá em hipóteses muito excepcionais, devidamente comprovadas, aptas a afastar o interesse público. [...] Tal interesse é presumido, só podendo ser afastada mediante demonstração expressa da sua ausência e do dolo da difamar." 
e a liberdade de informação, direito este com dupla titularidade: individual e transindividual, que a técnica de ponderação de regras, princípios e normas, funcionalmente mais flexível e profunda, eleva-se sobre a interpretação jurídica tradicional (subsunção), cujo enfoque, desta última, de certo modo, quase que se limita ao empenho de incorporar o caso concreto à norma abstrata vinculada.

Outrossim, na ausência de normas ou ante outros parâmetros legislativos constitucionalmente inaptos para dirimir o problema, a ponderação mostra-se, constitucionalmente, mais adequada para proceder com normas, valores ou interesses diversos e contraditórios, no desígnio pela aplicação do direito sem que se imponha ou afaste uma premissa sobre outra; isso, sim, fundamentando-se na análise de cada caso concreto e guiando-se por parâmetros de interpretação para avaliar o peso da cada um dos valores manifestados, considerando as circunstâncias e as normas envolvidas, a fim de poder proteger e conter, respectivamente, as pretensões ensejadas, ou seja, sopesar os interesses conforme o contexto do caso.

Quanto ao que concerne a respectiva conjectura aqui proposta, a tutela de ambos os direitos vem ocasionando, através de seus respectivos defensores, tanto na Doutrina e na Jurisprudência pátria como na sociedade em geral, entendimentos divergentes acerca do tema. Certa parcela, como representa Silva (2012, p. 48-49), entende que "a dignidade, como cláusula geral de tutela da personalidade, havida como fundamento da República Federativa do Brasil, deve prevalecer sobre todos os demais princípios". Mas, conclui que, entre o interesse coletivo e o particular, deve prevalecer o ensejo daquele.

No mesmo entendimento Diniz (2009, p. 163) defende a "necessidade de limitar o direito de informar da imprensa e o direito de o público ser informado, visto que podem gerar conflitos entre a ânsia informativa e lucrativa e interesses individuais de pessoas lesadas em sua imagem, privacidade, intimidade etc."

Entretanto, do lado oposto, podemos citar Tartuce $(2018$, p. 1304$)$ que diverge e afirma que:

[...] O direito à informação e à liberdade de imprensa ou de expressão tem sido reconhecido pelos julgadores das superiores instâncias no Brasil - especialmente do Supremo Tribunal Federal - como uma espécie de superdireito, a prevalecer, pelo menos em regra, sobre a tutela de outros direitos fundamentais ou da personalidade, caso da intimidade e da imagem, igualmente protegidos.

Outrossim, deve-se mencionar que em linhas posteriores, o mesmo autor reconhece que a "evolução doutrinária a respeito do tema" vem entendendo que a liberdade de expressão não é absoluta sobre os direitos da personalidade, como se pode constatar pelo enunciado 613 da VII Jornada de Direito Civil.

Assim, como foi verificado, na ausência de soluções regras rígidas e abstratas para lidar com eventuais casos de tensão e colisão entre os valores abordados, ou entre quaisquer outros, que possam apresentar-se (tanto que não seria factível assentar no direito positivo sobre como proceder-se ante cada uma das possíveis disputas), é que a técnica de decisão da ponderação se apresenta como a mais adequada para o intérprete/julgador aplicar a solução jurídica mais adequada para cada caso.

Do exposto, é possível afirmar que ambos os direitos encontram seus limites um no outro, reciprocamente, entre outros direitos também constitucionais. $\mathrm{E}$, por ambos se tratar de princípios jurídicos, resulta procedente que, nos casos concretos de colisão entre ambos, seja aplicado a técnica de solução de conflitos da ponderação, para avaliar e adequar certo equilíbrio, fundamentado, entre os interesses conflitantes, podendo ocorrer a cessão de certo grau de privacidade ou intimidade em prol da informação que apresente relevância ou benefício público, e vice-versa.

\section{REFERÊNCIAS}

\section{ALEXY, Robert. Teoría de los derechos}

fundamentales. Versão castelhana: Ernesto Garzón Valdés. - Madrid, Espanha: Centro de Estudios Políticos y Constitucionales, 1993. Título original: Theorie der Grundrechte. Suhrkamp-Verlag, 1986.

AMARAL, Francisco. Direito civil: introdução - 9. ed. rev., modif. e ampl. - São Paulo: Saraiva, 2017.

ÁVILA, Humberto Bergmann. A distinção entre princípios e regras e a redefinição do dever de 
proporcionalidade. Revista de direito administrativo - FGV, Rio de Janeiro/RJ, v. 215, p. 151-179, 1. tri. jan./mar. 1999. DOI http://dx.doi.org/10.12660/rda.v215.1999.47313. Disponível em:

http://bibliotecadigital.fgv.br/ojs/index.php/rda/iss ue/view/2448. Acesso em: 6 abr. 2020.

BARROSO, Luís Roberto. Liberdade de expressão versus direitos da personalidade. Colisão de direitos fundamentais e critérios de ponderação. In: SARLET, Ingo Wolfgang (org). Direitos fundamentais, informática e comunicação. Porto Alegre: Livraria do Advogado Ed., 2007.

BENTIVEGNA, Carlos Frederico Barbosa. Liberdade de expressão, honra, imagem e privacidade: os limites entre o lícito e o ilícito. Barueri-SP: Manole, 2019.

BITTAR, Carlos Alberto. Os direitos da personalidade - 8. ed., rev., aum. e mod. por Eduardo C. B. Bittar. - São Paulo: Saraiva, 2015.

CASTILHO, Ricardo. Direitos humanos - 2. ed. - São Paulo: Saraiva, 2012. - (Coleção sinopses jurídicas; v. 30).

CAVALIERI FILHO, Sergio. Programa de responsabilidade civil - 13.ed. São Paulo: Atlas, 2019.

DINIZ, Maria Helena. Curso de direito civil brasileiro, vol. 7: responsabilidade civil. 23. ed. reform. São Paulo: Saraiva, 2009.

GAGLIANO, Pablo Stolze; PAMPLONA FILHO, Rodolfo. Novo curso de direito civil, volume 1: parte geral - 14. ed. rev., atual e ampl. - São Paulo: Saraiva, 2012.

LOBO, Paulo. Constitucionalização dos institutos fundamentais do direito civil. 29 jan. 2018. Disponível em: http://genjuridico.com.br/2018/01/29/constitucion alizacao -do-direito-civil. Acesso em: 29 ago. 2019.

MIRANDA, Victor Vasconcelos. $\mathbf{O}$ direito à privacidade na era digital e as tutelas assecuratórias. Revista Fórum de Direito Civil RFDC, Belo Horizonte, ano 5, n. 12, p. 97-121, maio/ago. 2016
MORAES, Maria Celina Bodin de. Danos à pessoa humana: uma leitura civil-constitucional dos danos morais - Rio de Janeiro: Renovar, 2003.

PAESANI, Liliana Minardi. Direito e internet: liberdade de informação, privacidade e responsabilidade civil - 7. ed. - São Paulo: Atlas, 2014.

POMPEU, Gina Vidal Marcílio; POMPEU, Inês Mota Randal. Liberdade de expressão e informação em face dos direitos da personalidade: análise com base na ADI no 4.815. In: MENEZES, Joyceane Bezerra de; TEPEDINO, Gustavo (Coord.).

Autonomia privada, liberdade existencial e direitos fundamentais. Belo Horizonte: Fórum, 2019. p. 269-283. ISBN: 978-85-450-0585-8.

SANKIEVICZ, Alexandre. Liberdade de expressão e pluralismo: perspectivas de regulação - São Paulo: Saraiva, 2011 - (Série IDP).

SARLET, Ingo Wolfgang; MARINONI, Luiz Guilherme; e MITIDIERO, Daniel. Curso de direito constitucional - 8. ed. - São Paulo: Saraiva Educação, 2019

SILVA, Regina Beatriz Tavares da. Sistema protetivo dos direitos da personalidade. In: SILVA, Regina Beatriz Tavares da; SANTOS, Manoel J. Pereira dos (coords). Responsabilidade civil: responsabilidade civil na internet e nos demais meios de comunicação. 2. ed. São Paulo: Saraiva, 2012, p. 2171 - (Série GVlaw).

SILVA, Roberto de Abreu e. Responsabilidade Civil Constitucional. Revista da Escola de Magistratura do Estado do Rio de Janeiro - EMERJ, Rio de Janeiro/RJ, ano 2001, v. 4, n. 16, p. 60-72. ISSN2236-8957. Disponível em: http://www.emeri.tjri.jus.br/revistaemeri online/e dicoes/revista16/revista16 sumario.htm. Acesso em: 10 out. 2019.

TARTUCE, Flávio. Manual de responsabilidade civil: volume único. - São Paulo: Método. 2018. 